Jurnal Onoma: Pendidikan, Bahasa dan Sastra

ISSN 2443-3667 (Print)

PBSI FKIP Universitas Cokroaminoto Palopo

ISSN 2715-4564 (Online)

Volume 7 Nomor1 Tahun 2021

\title{
Sapaan Kekerabatan pada Guyub Tutur Bahasa Lio
}

\author{
Maria Floriana Serlin \\ Pendidikan Bahasa dan Sastra, Universitas FLores, Indonesia \\ mariaflorianaserlin6@gmail.com
}

\begin{abstract}
Abstrak
Penelitian ini bertujuan untuk mendeskripsikan tentang sapaan kekerabatan pada guyub tutur bahasa Lio dengan menggunakan teori sosiolinguistik. Pendekatan yang digunakan dalam penelitian ini adalah pendekatan kualitatif. Pengumpulan data menggunakan metode simak, cakap dan pancing. Artinya peneliti secara langsung berkomunikasi dengan informan untuk menggali informasi tentang sapaan kekerabatan pada guyub tutur bahasa Lio. Kedua metode ini dilengkapi dengan teknik wawancara, catat, dan dokumentasi. Hasil penelitian menunjukkan bahwa dalam hubungan kekerabatan berdasarkan garis keturunan (pertalian langsung) pada guyub tutur bahasa Lio kabupaten Ende terdapat 16 kata sapaan yakni Ema, Ine, Babo, Mamo, Eda, No `o, Weta, Nara, Ka 'e, Aji, Ana mamo, Ana embu, Ame du'a, Ine du'a, Ame Lo'o dan Ine Lo'o. sengkan ada 13 kata sapaan kekerabatan berdasarkan garis perkawinan dalam guyub tutur bahasa Lio adalah Ema (tu 'a), Ine (tu'a), (Ana) tu 'a, Ane, Tata/fai eda, No `o, Haki no`o, Weta, Nara, Kae, Aji, Ipa, dan Eja.

Kata Kunci; Sapaan, Kekerabatan, Bahasa Lio
\end{abstract}

\begin{abstract}
This study aims at describing the kinship greeting in Lio's speech using sociolinguistic theory. The approach used in this study is a qualitative approach. Data collection uses the method of listening, proficient and fishing rod. This means that researchers directly communicate with informants to gather information about kinship greetings in Lio's spoken language. Both of these methods are complemented by interview, note-taking, and documentation techniques.The results showed that in the kinship relationship based on lineage (direct linkage) in Lio's speech in Ende district, there were 16 greeting words, namely Ema, Ine, Babo, Mamo, Eda, No'o, Weta, Nara, Ka 'e, Aji, Ana mamo, Ana embu, Ame du'a, Ine du'a, Ame Lo'o and Ine Lo'o. It is stressful that there are 13 kinship greeting words based on the line of marriage in Lio's speech, namely Ema (tu'a), Ine (tu'a), (Ana) tu'a, Ane, Tata / Fai Eda, No`o, Haki no`o, Weta, Nara, Kae, Aji, Ipa, and Eja.
\end{abstract}

Keywords; Greetings, Kinship, Lio Language

\section{Pendahuluan}

Penggunaan bahasa dalam interaksi sosial sangatlah beragam. Variasi-variasi penggunaan bahasa sangat menarik untuk dipelajari dan dibahas secara ilmiah. Bentuk variasi kebahasaan yang sering menyertai penggunaan bahasa lisan adalah sapaan. Hal ini mengindikasikan bahwa bentuk-bentuk tutur sapa yang digunakan sebagai sistem sapaan sarat akan makna sosial budaya. Penggunaan sapaan sangat dipengaruhi oleh normanorma kebahasaan dan pola-pola budaya berbahasa sebagai salah satu wujud perilaku sosial. Hal ini berarti bahwa setiap pilihan variasi bentuk tutur sapa mengandung nilai-nilai tertentu, antara lain berupa sikap dan perasaan hormat atau pun persaudaraan terhadap pihak yang disapa (Kridalaksana, 2012:32).

Sapaan adalah cara mengacu seseorang di dalam interaksi linguistik yang dilakukan secara langsung (Crystal dalam Aslinda, dkk. 2010:4). Kata sapaan terms of address hanya dipakai untuk menyapa lawan bicara atau pesona kedua. Penggunaan istilah sapaan yang 
tepat terhadap seseorang dapat terjadi jika diawali dengan pengenalan tentang istilah sebutan apa yang diberikan kepada orang yang disapa (pesapa) itu. Hal ini berarti bahwa istilah menyapa dipakai jika kita meyapa atau memanggil seseorang untuk menjadi mitra bicara atau orang kedua, sedangkan istilah menyebut dipakai jika kita berbicara dengan orang lain dan menyebut-nyebut orang yang tidak terlihat dalam situasi pembicaraan atau sebutan kepada orang ketiga.

Mahmud (2012:15) menyatakan bahwa kekerabatan merupakan suatu bentuk hubungan sosial yang terjadi karena keturunan consanguinity dan perkawinan affinity. Dalam menentukan hubungan kekerabatan berdasarkan perkawinan dapat dilihat dari garis keturunan terlebih dahulu. Masyarakat itu memakai garis keturunan ibu atau matrilineal maka pihak ayah yang menjadi kerabat berdasarkan garis perkawinan. Namun, masyarakat yang memakai garis keturunan ayah maka pihak ibu yang menjadi kerabat berdasarkan perkawinan.

Sapaan kekerabatan ialah sapaan yang berhubungan dengan pertalian darah dan pertalian perkawinan.Pertalian darah disebut pertalian langsung, sedangkan pertalian perkawinan disebut pertalian tak langsung (Aslinda, dkk. 2010). Istilah kekerabatan (kinship terms) berhubungan dengan pertalian darah dan keturunansapaan dalam bertutur sapa, baik dalam lingkaran kekerabatan maupun di luar kekerabatan.

Setiap daerah memiliki sistem sapaan yang berbeda. Kata sapaan tersebut digunakan untuk menjaga sistem kekerabatan dalam berbahasa di daerah tertentu. Tingginya globalisasi dan mobilitas sosial, serta perluasan penyebaran media masa telah mempengaruhi perkembangan penggunaan kata sapaan dan mengancam punahnya kata sapaan disetiap daerah termasuk kata sapaan pada guyub tutur bahasa Lio. Oleh karena itu, kata sapaan kekerabatan sangat penting untuk dilestarikan agar tidak punah.

Suku Lio adalah suku tertua dan suku terbesar yang ada di Pulau Flores. Masyarakat (guyub tutur) suku Lio pada umumnya menempati Kecamatan Wolowaru, Kecamatan Ndona, Kecamatan Ndona Timur, Kecamatan Detusoko, Kecamatan Lio Timur, kecamatan Maurole, Kecamatan Detukeli, Kecamatan Ndori, Kecamatan Kelimutu, beberapa wilayah di Kecamatan Maukaro, Kecamatan Lepembusu Kelisoke, Kecamatan Kotabaru, Kecamatan Wolojita dan Kecamatan Wewaria. Populasi masyarakat Lio mendominasi hampir $85 \%$ wilayah kabupaten Ende. Suku Lio juga menempati bagian barat wilayah Kabupaten Sikka yakni: Kecamatan Paga, Kecamatan Mego, Kecamatan Tanawawo, dan Kecamatan Magepanda.

Dalam komunikasi sehari-hari masyarakat suku Lio menggunakan bahasa Lio. Bahasa Lio adalah salah satu bahasa lokal atau bahasa daerah, atau juga bahasa etnik Lio yang ada di Flores Tengah, Nusa Tenggara Timur. Bahasa Lio tergolong bahasa vokalis setelah mengalamiperubahan atau penanggalan konsonan protobahasa Flores. Sebagai bahasa lokal yang menyatu dengan dan menjadi ciri jati diri guyub tutur pemilik dan para pewarisnya yakni para anggota guyub tutur bahasa Lio, bahasa Lio mengemban fungsifungsi yang sangat penting bagi masyarakat Lio. Bahasa Lio adalah perekat persatuan sebagai orang Lio, sarana komunikasi dan interaksi verbal antarwarga etnik Lio, perekam dan pengalih (transmisi) kebudayaan Lio antar generasi; kebudayaan Lio dalam pelbagai seginya (Mbete, 2006:9). Bahasa Lio juga menjadi sarana pengungkap seni sastra dan 
budaya Lio, dan menjadi ciri pembeda jati diri Orang Lio dengan etnik-etnik lainnya di Flores dan Indonesia umumnya. Sebagai warisan sejarah dan elemen budaya masa lalu, bahasa Lio telah hidup dan berfungsi bagi guyub tuturnya sejak ratusan bahkan ribuan tahun silam. Adat istiadat tradisi, dan kebudayaan Lio diungkapkan dan diwadahi dalam bahasa Lio.

Pada guyub tutur bahasa Lio terdapat identitas/panggilan/sapaan yang menunjukan status dalam suatu kekerabatan(sanak)dalam menjalin hubungan kekerabatan. Identitas ini merupakan suatu pertalian yang melekat pada diri seseorang yang menunjukan hubungan antara yang satu dengan yang lain yang dikenal dengan sebutan kunu woe. Hal ini dapat mempertegas hubungan sanak saudara yang hidup dalam wilayah Ende lio maupun sudah berada di daerah lain.

Hubungan kekerabatan ini tidak dibatasi dengan perbedaan keyakinan beragama maupun strata sosial dalam masyarakat. Akan tetapi dalam konteks untuk membangun ikatan keluarga (perkawinan) maka sistem kekerabatan ini yang menjadi acuan sehingga tidak terjadi kesalahan dalam memilih pasangan hidup. Misalnya anak laki-laki dari saudari perempuan boleh menikah dengan anak perempuan dari saudara laki-laki (Ana Eda \& Ana No'o).

Berdasarkan uraian yang telah dikemukakan, jelaslah betapa pentingnya kata sapaan dalam budaya guyub tutur bahasa Lio. Maka dari itu peneliti berkeinginan dan tertarik untuk meneliti, memahami, dan mengkaji sebagai sebuah hasil karya budaya bahasa (kearifan lokal) yang erat dengan perkembangan berpikir, memahami, dan bertindak sebagai sebuah sistem yang unik dan khas pada guyub tutur bahasa Lio.Dengan alasan itu peneliti tertarik dan berniat menguraikan persoalan dimaksud dengan mengangkat judul "Sapaan Kekerabatan pada Guyub Tutur Bahasa Lio". Sejalan dengan uraian tentang latar belakang pelaksanaan penelitian, berikut rumusan masalah yang disajikan dalam penelitian ini adalah bagaimanakah penggunaan sapaan kekerabatan pada guyub tutur bahasa Lio?.

\section{Kerangka Teori}

Teori yang digunakan dalam penelitian ini adalah teori sosiolinguistik. Sosiolinguistik didefinisikan sebagai ilmu yang membahas tentang aspek-aspek kemasyarakatan bahasa, khususnya perbedaan-perbedaan (variasi) yang terdapat dalam bahasa yang berkaitan dengan faktor-faktor kemasyarakatan. Sosiolinguistik merupakan ilmu antardisiplin antara sosiologi dengan linguistik, dua bidang ilmu empiris yang mempunyai kaitan erat. Sosiologi merupakan kajian yang objektif dan ilmiah mengenai manusia di dalam masyarakat, lembaga-lembaga, danproses sosial yang ada di dalam masyarakat. Kajian sosiolingustik sebagai cabang lingustik memandang dan menetapkan kedudukan bahasa dalam hubungannya dengan pemakaian bahasa didalam masyarakat, karena itu didalam kehidupan bermasyarakat manusia tidak lagi sebagai individu, akan tetetapi sebagai masyarakat sosial. Sosiolinguistik sebagai ilmu interdisipliner menggarap masalah-masalah kebahasaan dalam hubunganya dengan faktor-faktor sosial, situasional, dan kulturalnya (Chaer, $2010: 31$ ). 
Dalam ranah sosiolinguistik, bahasa dan masyarakat sosial merupakan satu kesatuan. Belajar bahasa atau mengamati perubahan gejala bahasa perlu memperhatikan konteks sosial tempat bahasa itu tumbuh dan berkembang. Oleh karena itu, sesorang tidak dapat memahami bahasa tanpa mengetahui budaya dan siklus sosialnya dan sebaliknya seseorang tidak dapat memahami budaya suatu masyarakat tanpa memahami bahasanya.

Setiap tindak ujaran yang dihasilkan dalam peristiwa ujaran, tercipta karena adanya interaksi sosial (Utami, 2010:5). . Salah satu segi yang penting dalam interaksi dimaksud adalah terbentuknya sistem penyapaan atau tutur sapa. Sehingga dalam penyapaan (tutur sapa), interaksi dilakukan dengan mempertautkan seperangkat katakata (frasa) atau ungkapan-ungkapan untuk menyebut dan memanggil para pelaku dalam suatu peristiwa bahasa.

Menurut Mahmud (2012:15) sapaan merupakan kata atau frasa untuk saling merujuk dalam pembicaraan dan dapat berbeda beda menurut sifat hubungan diantara pembicara itu, misalnya anda, ibu dan saudara.Sapaan juga diartikan sebagai ajakan untuk bercakap, teguran, atau ucapan. Oleh karena itu, sapaan sangat berkaitan erat nama dan sebutan nama yang dimaksud ialah kata untuk menyebut atau memanggil orang (panggilan, nama, ataupun gelar).

Kekerabatan adalah unit-unit sosial yang terdiri dari beberapa keluarga yang memiliki hubungan darah atau hubungan perkawinan (. Anggota kekerabatan terdiri atas ayah, ibu, anak, menantu, cucu, kakak, adik, paman, bibi, kakek, nenek dan seterusnya. Seseorang dikatakan kerabat apabila ada pertalian darah atau pertalian langsung dan pertalian perkawinan atau tidak langsung sehingga dapat disimpulkan bahwa seseorang disebut berkerabat jika ada pertalian darah (consanguity) atau pertalian perkawinan (affinity). Oleh sebab itu, kekerabatan memegang peranan penting dalam membina ikatan kelompok dan rasa kebersamaan karena kekerabatan tersebut menunjukkan kedudukan para anggotanya.

\section{Metode Penelitian}

Penelitian ini menggunakan pendekatan kualitatif untuk meneliti kondisi objek yang alamiah, sehingga proses, hipotesis, turun ke lapangan (objek penelitian), analisis data dan kesimpulannya mempergunakan aspek-aspek kecenderungan, non perhitungan numerik, situasional deskriptif, interview mendalam dan analisis data. Penelitian ini merupakan penelitian sosiolinguistik. Penelitian ini menggunakan metode kualitatif, karena penelitian ini bersifat deskriptif, dan cenderung menggunakan analisis. Suhardi, 2012: 15) mengatakan kajian sosiolinguistik lebih bersifat kualitatif.

Pengumpulan data menggunakan metode simak, cakap dan pancing. Artinya peneliti secara langsung berkomunikasi dengan informan untuk menggali informasi tentang sapaan kekerabatan pada guyub tutur bahasa Lio. Kedua metode ini dilengkapi dengan teknik wawancara, catat, dan dokumentasi. Data dalam penelitian ini adalah data lisan berupa sapaan kekerabatan pada masyarakat suku Lio. Data yang diperoleh bersumber dari informan yang merupakan masyarakat suku Lio. Data yang terkumpul dianalisis secara induktif pada saat dan setelah penelitian berlangsung. Hasil analisis dinyatakan dalam bentuk naratif/bukan dalam perhitungan angka-angka (Mahsun, 2011:32). 
Secara singkat dan prosedural, proses analisis data dilakukan sejak awal penelitian sampai pengumpulan data selesai. Ada tiga tahapan yang dilakukan dengan model ini, yaitu:

1. Reduksi Data

Tahap reduksi data adalah tahap menajamkan atau mengorganisasikan data, sehingga kesimpulan dapat diverifikasi untuk dijadikan temuan penelitian terhadap masalah yang diteliti.Pada tahap ini, peneliti mengumpulkan seluruh data lapangan, menafsirkan, mengkategorikan dan menyeleksi masing-masing data yang relevan dengan fokus masalah yang diteliti.

2. Penyajian Data

Penyajian data adalah tahap dimana peneliti menyusun data yang telah dikelompokkan berdasarkan fokus penelitian, sehingga memberikan gambaran yang mengarah pada pemerolehan jawaban atas masalah penelitian.

3. Penarikan Kesimpulan

Penarikan kesimpulan adalah tahap dimana peneliti menginterpretasi data untuk menghasilkan suatu temuan.Kegiatan penyimpulan diikuti dengan pengecekan keabsahan data.

\section{Hasil dan Pembahasan}

Berdasarkan jenis dan fungsinya, kata sapaan dikelompokkan atas 2 yakni, 1). Kata sapaan kekerabatan yang meliputi sapaan kekerabatan berdasarkan garis keturunan/pertalian langsung dan kata sapaan berdasarkan garis perkawinan (pertalian tak langsung), 2). Kata sapaan dalam hubungan non kekerabatan (masyarakat luas) (Wibowo, 2015:7). Hal ini senada dengan apa yang dikemukakan oleh Mahmud (2012:19) bahwa kekerabatan merupakan suatu bentuk hubungan sosial yang terjadi karena keturunan (consanguinity) dan perkawinan (affinity).

Pada guyub tutur Lio dalam menjalin hubungan kekerabatan terdapat identitas/panggilan/sapaan yang menunjukan status dalam suatu kekerabatan (sanak). Identitas ini merupakan suatu pertalian yang melekat pada diri seseorang yang menunjukan hubungan antara yang satu dengan yang lain yang dikenal dengan sebutan kunu woe. Hal ini dapat mempertegas hubungan sanak saudara yang hidup dalam wilayah suku Lio maupun yang sudah berada di daerah lain. Sapaan dalam hubungan kekerabatan yang sering digunakanoleh guyub tutur Lio meskipun dalam suatu sub etnis Ende Lio terdapat beberapa perbedaan penyebutan pangilan namun dalam menunjukan kapasitasnya tetaplah sama.

Hubungan kekerabatan ini tidak dibatasi dengan perbedaan keyakinan beragama maupun strata sosial dalam masyarakat. Akan tetapi dalam konteks untuk membangun ikatan keluarga (perkawinan) maka sistem kekerabatan ini yang menjadi acuan sehingga tidak terjadi kesalahan dalam memilih pasangan hidup. Dalam budaya guyub tutur Lio anak laki-laki dari saudari perempuan boleh menikah dengan anak perempuan dari saudara laki-laki (perkawinan Ana Eda \& Ana No'o).

Dalam penelitian ini peneliti hanya membahas tentang kata sapaan kekerabatan yang digunakan guyub tutur Lio berdasarkan garis keturunan atau pertalian langsung dan 
sapaan kekerabatan berdasarkan garis perkawinan (pertalian tak langsung). Berdasarkan hasil analisis data, sapaan kekerabatan menurut budaya pada guyub tutur bahasa Lio diuraikan sebagai berikut.

\section{a. Sapaan kekerabatan}

\section{Sapaan Kekerabatan berdasarkan Garis Keturunan (Pertalian Langsung)}

Kata sapaan kekerabatan berdasarkan garis keturunan merupakan kata sapaan yang digunakan untuk menyapa orang yang mempunyai hubungan darah. Bentuk kata sapaan kekerabatan berdasarkan garis keturunan dalam bahasa Lio penggunaannya ditentukan oleh keturunan patrilineal atau menurut garis keturunan ayah. Berdasarkan hasil analisis data ditemukan bahwa dalam hubungan kekerabatan berdasarkan garis keturunan (pertalian langsung) pada budaya masyarakat suku Lio kabupaten Ende terdapat 16 kata sapaan. Keenambelas kata sapaan tersebut dapat dilihat pada tabel 1.

Tabel 1. Kata sapaan berdasarkan garis keturunan

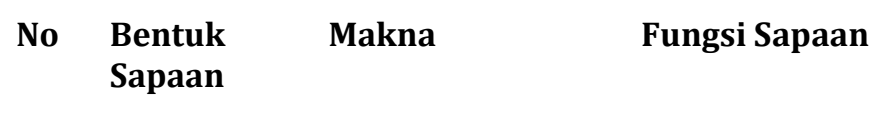

\begin{tabular}{|c|c|c|c|}
\hline 1 & Ema & Ayah & Kata sapaan ema digunakan untuk menyapa ayah kandung \\
\hline 2 & Ine & Ibu & Kata Ine digunakan untuk menyapa ibu kandung \\
\hline 3 & Babo & Kakek & $\begin{array}{l}\text { Kata babo digunakan untuk menyapa kakek (orangtua laki-laki } \\
\text { dari ayah atau ibu) }\end{array}$ \\
\hline 4 & Mamo & Nenek & $\begin{array}{l}\text { Kata mamo digunakan untuk menyapa nenek (orangtua } \\
\text { perempuan dari ayah atau ibu) }\end{array}$ \\
\hline 5 & $E d a$ & Paman & Kata eda digunakan untu k menyapa saudara laki-laki dari ibu \\
\hline 6 & No`o & $\begin{array}{l}\text { Bibi (saudari dari } \\
\text { ayah) }\end{array}$ & $\begin{array}{l}\text { Kata no`o digunakan untuk menyapa bibi/ saudari perempuan } \\
\text { dari ayah }\end{array}$ \\
\hline 7 & Weta & Saudari & $\begin{array}{l}\text { Kata weta digunakan untuk menyapa saudari perempuan } \\
\text { kandung atau sepupu. }\end{array}$ \\
\hline 8 & Nara & Saudara & $\begin{array}{l}\text { Kata nara digunakan untuk menyapa saudara laki-laki dan juga } \\
\text { sepupu }\end{array}$ \\
\hline 9 & $\mathrm{Ka}{ }^{\prime} \mathrm{e}$ & Kakak & Kata ka`e digunakan untuk menyapa kakak \\
\hline 10 & $A j i$ & Adik & Kata aji digunakan untuk menyapa adik \\
\hline
\end{tabular}




\begin{tabular}{|c|c|c|c|}
\hline 11 & Ana mamo & Cucu & $\begin{array}{l}\text { Kata ana mamo biasa digunakan untuk menyapa cucu, dalam } \\
\text { komunikasi sehari-hari sering disingkat menjadi mamo }\end{array}$ \\
\hline 12 & Ana embu & Cicit & $\begin{array}{l}\text { Kata ana embu dalam komunikasi sehari-hari biasa disingkat } \\
\text { menjadi embu,digunakan untuk menyapa cicit }\end{array}$ \\
\hline 13 & Ame du`a & $\begin{array}{l}\text { Bapak } \\
\text { besar/kakak ayah }\end{array}$ & $\begin{array}{l}\text { Kata ame } d u^{\prime} \text { a biasa disingkat menjadi } d u^{\prime} a \text {, digunakan untuk } \\
\text { menyapa kakak laki-laki ayah. Namun ada juga yang } \\
\text { menggunakan kata ame }\end{array}$ \\
\hline 14 & Ine $d u^{\prime} a$ & $\begin{array}{l}\text { Ibu/mama besar } \\
\text { (kakak } \\
\text { perempuan dari } \\
\text { ibu) }\end{array}$ & $\begin{array}{l}\text { Kata ine } d u^{`} \text { 'a biasa disingkat menjadi } d u^{`} a \text {, digunakan untuk } \\
\text { menyapa kakak perempuan dari ibu. Namun ada juga yang } \\
\text { menggunakan kata ine. }\end{array}$ \\
\hline
\end{tabular}

$\begin{array}{lll}\text { Ame Lo`o } & \begin{array}{l}\text { Bapak Kecil (adik } \\ \text { ayah) }\end{array} \\ 16 \text { Ine Lo`o } & \begin{array}{l}\text { Mama keci (adik } \\ \text { ibu) }\end{array}\end{array}$

\section{Sapaan Kekerabatan berdasarkan garis perkawinan (pertalian tak langsung)}

Kekerabatan berdasarkan perkawinan merupakan kekerabatan yang terjalin setelah terjadinya perkawinan. Dalam menentukan kerabat berdasarkan perkawinan dapat dilihat dari garis keturunan terlebih dahulu. Masyarakat itu memakai garis keturunan ibu atau matrilineal maka pihak ayah yang menjadi kerabat berdasarkan garis perkawinan. Namun,masyarakat yang memakai garis keturunan ayah maka pihak ibu yang menjadi kerabat berdasarkan perkawinan. Kekerabatan berdasarkan garis perkawinan dalam masyarakat suku Lio memakai garis keturunan ayah (patrilineal). Berdasarkan garis perkawinan ada 13 kata sapaan yang digunakan oleh masyarakat suku Lio. Ketiga belas kata sapaan tersebut dapat dilihat pada tabel 2. Adapun kata sapaan tersebut adalah ine/ema tu`a,ana tu`a, ane, tata/fai eda, haki no`o, eja, ipa, nara, weta, ka`e, aji.

\section{Tabel 2. Sapaan Kekerabatan berdasarkan Garis Perkawinan (Pertalian tak Langsung)

\begin{tabular}{llll}
\hline No & $\begin{array}{l}\text { Bentuk } \\
\text { Sapaan }\end{array}$ & Makna & Fungsi Sapaan \\
& &
\end{tabular}

\begin{tabular}{llll}
\hline $\mathbf{1}$ & Ema (tu`a) & Ayah mertua & Kata sapaan ema digunakan untuk menyapa ayah mertua \\
$\mathbf{2}$ & Ine (tu`a) & Ibu mertua & Kata Ine digunakan untuk menyapa ibu mertua
\end{tabular}


Volume 7 Nomor1 Tahun 2021

\begin{tabular}{|c|c|c|c|}
\hline 3 & (Ana) tu`a & Menantu & $\begin{array}{l}\text { Kata Tu 'a digunakan untuk menyapa menantu baik } \\
\text { menantu laki-laki maupun perempuan. }\end{array}$ \\
\hline 4 & Ane & Menantu & $\begin{array}{l}\text { Kata ane digunakan oleh seorang paman untuk menyapa } \\
\text { menantu laki-laki (suami dari kemenakan) }\end{array}$ \\
\hline 5 & Tata/fai eda & Istri paman & $\begin{array}{l}\text { Kata tata digunakan untu k menyapa istri dari paman } \\
\text { (saudara laki-laki dari ibu) }\end{array}$ \\
\hline 6 & No`o & Bibi/ibu mertua & $\begin{array}{l}\text { Kata no`odalam hubungan kekerabatan berdasarkan } \\
\text { perkawinan dalam masyrakat suku Lio digunakan oleh } \\
\text { seorang menantu wanita untuk menyapa ibu mertua }\end{array}$ \\
\hline 7 & Haki no`o & Om/paman & Kata haki no`o digunakan untuk menyapa suami dari bibi \\
\hline 8 & Weta & Saudari & Kata weta digunakan untuk menyapa istri \\
\hline 9 & Nara & Saudara & Kata naradigunakan untuk menyapa suami \\
\hline 10 & Kae & Kakak & $\begin{array}{l}\text { Kata kae digunakan untuk menyapa kakak ipar (kakak dari } \\
\text { suami atau istri) }\end{array}$ \\
\hline 11 & $\mathrm{Aji}$ & Adik & $\begin{array}{l}\text { Kata aji digunakan untuk menyapa adik ipar (adik dari istri } \\
\text { atau suami) }\end{array}$ \\
\hline 12 & Ipa & Ipar & $\begin{array}{l}\text { Kata ipa digunakan oleh saudari perempuan untuk } \\
\text { menyapa istri dari saudara laki-laki demikian juga } \\
\text { sebaliknya }\end{array}$ \\
\hline 13 & Eja & Ipar & $\begin{array}{l}\text { Kata eja digunakan oleh saudara laki-lakiuntuk menyapa } \\
\text { suami dari saudari perempuannya demikian pula } \\
\text { sebaliknya. }\end{array}$ \\
\hline
\end{tabular}




\section{Simpulan}

Salah satu variasi penggunaan bahasa adalah penggunaan sapaan (sistem tutur sapa/ sistem sapaan. Hal ini mengindikasikan bahwa bentuk-bentuk tutur sapa yang digunakan sebagai sistem sapaan sarat akan makna sosial budaya. Artinya penggunaan sapaan sangat dipengaruhi oleh norma-norma kebahasaan dan pola-pola budaya berbahasa sebagai salah satu wujud perilaku sosial. Hal ini berarti bahwa setiap pilihan variasi bentuk tutur sapa mengandung nilai tertentu, antara lain berupa sikap dan perasaan hormat ataupun persaudaraan terhadap pihak yang disapa (Mahmud, 2012: 21).

Berdasarkan hasil penelitian disimpulkan bahwa pada guyub tutur bahasa Lio terdapat 2 jenis sapaan kekerabatan yakni, 1). Sapaan kekerabatan berdasarkan garis keturunan/pertalian langsung, dan 2). Sapaan kekerabatan berdasarkan garis perkawinan (pertalian tak langsung). Penggunaan sapaan kekerabatan dalam guyub tutur bahasa Lio menggambarkan betapa pentingnya hubungan kekerabatan dalam menentukan penggunaan sapaan yang tepat terhadap seseorang dalam berkomunikasi.

Asas hubungan kekerabatan masih dapat dipertahankan oleh guyub tutur bahasa Lio agar keturunan yang diperoleh lewat hubungan perkawinan, keturunan dan darah dapat terjaga dengan baik. Budaya pada guyub tutur Lio menekankan aspek keseragaman dalam menjalankan hubungan kekerabatan yang pasti agar tidak membingungkan anak dan cucu di kemudian hari.

Berdasarkan hasil analisis data ditemukan bahwa dalam hubungan kekerabatan berdasarkan garis keturunan (pertalian langsung) pada guyub tutur bahasa Lio kabupaten Ende terdapat 16 kata sapaan yakni Ema, Ine, Babo, Mamo, Eda, No`o, Weta, Nara, Ka'e, Aji, Ana mamo, Ana embu, Ame du'a, Ine du'a, Ame Lo'o dan Ine Lo'o. Sapaan kekerabatan berdasarkan garis perkawinan dalam guyub tutur Lio adalah Ema (tu'a), Ine (tu`a), (Ana) tu'a, Ane, Tata/fai eda, No`o, Haki no`o, Weta, Nara, Kae, Aji, Ipa, dan Eja.

\section{Daftar pustaka}

Aslinda dan Syafyaya, Leni. 2010. Pengantar Sosiolinguistik. Bandung : Refika Aditama Chaer, Abdul \& Leonie Agustina. 2010. Sosiolinguistik : Perkenalan Awal. Jakarta: Rineka Cipta

Kridalaksana, Harimurti.2012. Kamus Linguistik. Jakarta: PT. Gramedia Mahmud dan Suntana, Ija. 2012. Antropologi Pendidikan. Bandung : Pustaka Setia Mahsun. 2011. Metode Penelitian Bahasa: Tahapan Strategi, Metode \& Teknik. Jakarta: PT. Raja Grafindo Persada

Mbete, Aron Meko dkk. 2006. Khazanah Budaya Lio-Ende. Ende: Pustaka Larasan.

Suhardi, Basuki. 2012. Pedoman Penelitian Sosiolinguistik. Jakarta: Pusat bahasa Departemen Pendidikan Nasional

Utami, Santi Pratiwi Tri. 2010. "Realisasi Kesantunan Berbahasa: Upaya Pengoptimalan Peran Bahasa Indonesia Sebagai Pemersatu bangsa" dalam Proseding PIBSI XXXII

Wibowo, R. Mashudi dan Agustin Retraningsih. 2015. "Dinamika Bentuk Sapaan Sebagai Refleksi Sikap Berbahasa Masyarakat Indonesia”. Jurnal Humaniora (Online) Vol. 27, No. 32015 (http://jurnal.ugm.ac.id) Diakses tanggal 7 Januari 2020

Sugiyono. 2012. Metode Penelitian Kuantitatif Kualitatif dan R\&D. Bandung: Alfabeta 